\title{
Microbial Profiles of Rhizosphere and Bulk Soil Microbial Communities of Biofuel Crops Switchgrass (Panicum virgatum L.) and Jatropha (Jatropha curcas L.)
}

\author{
Doongar R. Chaudhary, ${ }^{1,2}$ Jyotisna Saxena, ${ }^{1}$ Nicola Lorenz, ${ }^{1}$ \\ Linda K. Dick, ${ }^{1}$ and Richard P. Dick ${ }^{1}$ \\ ${ }^{1}$ School of Environment and Natural Resources, The Ohio State University, 2021 Coffey Road, Columbus, OH 43210, USA \\ ${ }^{2}$ Discipline of Wasteland Research, Central Salt and Marine Chemicals Research Institute, Council of Scientific and Industrial Research, \\ G.B. Marg, Bhavnagar, Gujarat 364002, India
}

Correspondence should be addressed to Richard P. Dick, richard.dick@snr.osu.edu

Received 22 September 2011; Revised 4 February 2012; Accepted 6 February 2012

Academic Editor: Walter Willms

Copyright (c) 2012 Doongar R. Chaudhary et al. This is an open access article distributed under the Creative Commons Attribution License, which permits unrestricted use, distribution, and reproduction in any medium, provided the original work is properly cited.

\begin{abstract}
The production of biofuels from the low-input energy crops, switchgrass (Panicum virgatum L.) and jatropha (Jatropha curcas L.), is a sustainable approach that can provide more usable energy and environmental benefits than food-based biofuels. Plant rhizosphere affects the microbial community structure due to variations in root exudation rates and residue chemistry. The objective of this investigation was to determine the profiles of microbial communities associated with rhizosphere and bulk soils of switchgrass or jatropha using phospholipid fatty acid (PLFA) analysis and length heterogeneity PCR (LH-PCR). Switchgrass soil contained a significantly $(P<0.05)$ higher abundance of Gram-positive (i14:0, i15:0, a15:0), Gram-negative $(16: 1 \omega 5 c, 16: 1 \omega 7 c$, 18:1 $\omega 5 \mathrm{c})$, and saturated (14:0,15:0) PLFAs compared to jatropha soil, whereas jatropha had a higher abundance of fungal (18:2 $\omega 6$, 9c), 18:1 $\omega 9 c, 20: 1 \omega 9 c$, and 18:0 PLFAs compared to switchgrass soil. Irrespective of plant type, rhizosphere soil contained a significantly $(P<0.05)$ higher abundance of saturated PLFAs $(16: 0,18: 0,20: 0)$, actinomycetes $(10 \mathrm{Me} 17: 0)$, and fungal (18:2 $\omega 6$, 9c) PLFAs compared to bulk soil; whereas bulk soil had higher abundance of saturated (14:0), Gram-negative (16:1 $\omega 9 \mathrm{c}, 16: 1 \omega 5 \mathrm{c}$,

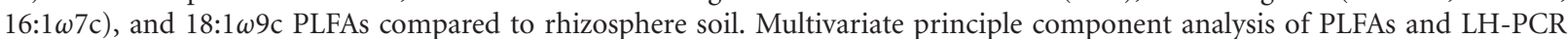
percent relative peak areas successfully differentiated the microbial communities of rhizosphere and bulk soils of switchgrass and jatropha.
\end{abstract}

\section{Introduction}

The increasing consumption of energy, limited availability of fossil fuels, and environmental pollution from exhaust emissions have created a great demand for biofuels that can be produced from renewable biomass. This has also resulted in a renewed interest in agricultural production of high yielding biofuel crops and energy conversion technologies necessary to achieve this goal. Currently, switchgrass (Panicum virgatum L.) and jatropha (Jatropha curcas L.) are the two main energy crops employed for bioethanol and biodiesel production, respectively [1]. Both switchgrass and jatropha are low maintenance, high yielding crops that can be grown on marginal lands with low agricultural inputs. Hence, both of these crops can be used as sustainable energy sources for producing renewable transportation fuels [1].

The rhizosphere is the volume of soil adjacent to the plant roots that plays a significant role in plant health and soil fertility. Actively growing roots secrete a diverse array of organic root exudates that stimulate the growth of microbial populations present in the rhizosphere, resulting in a microbial community structure at soil-root interface (i.e., rhizosphere) that is distinct from that in the bulk soil [2]. The rhizosphere microbial population promotes plant growth and health by catabolizing organic matter, mineralizing nutrients, fixing $\mathrm{N}_{2}$, and protecting from pests 
and pathogens [2]. The plant species and root zone can also affect the structural and functional diversity of rhizosphere microbial community due to variations in root exudation and rhizodeposition in different zones [3]. It is, therefore, important to understand the influence of plant roots on the composition of microbial community in the rhizosphere and the bulk soil of crops.

There is virtually no information on how microbial communities are affected by switchgrass or jatropha. Therefore, the objective of this study was to compare the microbial community composition of rhizosphere and bulk soil of two energy crops: switchgrass and jatropha with the cultureindependent techniques phospholipid fatty acid (PLFA) and length heterogeneity PCR (LH-PCR).

Phospholipid fatty acids are a major component of microbial membranes and are of interest as biomarkers because they are derived from viable cells (upon cell death the phosphate group is rapidly cleaved) and they provide information on a range of microbial properties: total biomass, physiological stress, and functional community composition [4]. In contrast, the LH-PCR method is based on nucleic acid analysis and utilizes the natural variations in the sequence length of small subunit (SSU) of $16 \mathrm{~S}$ ribosomal DNA sequences to distinguish microorganisms [5]. A fluorescent-labeled primer is used to amplify the sequences originating from microorganisms, which are later separated by gel electrophoresis and detected by laserinduced fluorescence with an automated gene sequencer [5]. The metagenomic profile of a particular soil thus obtained can be compared and contrasted with other soil samples [5].

\section{Materials and Methods}

2.1. Soil. The soil used in this study was collected in July 2009 from the Waterman Dairy Farm at The Ohio State University, Columbus, OH. The soil is classified as Crosby silt loam (a Stagnic Luvisol in the FAO/WSR classification and a fine, mixed, mesic Aeric Ochraqualf in the USDA classification). The initial total $\mathrm{C}$ and $\mathrm{N}$ contents of the soil were $1.32 \%$ and $0.09 \%$, respectively, and $\mathrm{pH}$ was 7.2 . Field moist soil was homogenized by passing through a $4 \mathrm{~mm}$ sieve.

2.2. Experimental Conditions. The seedlings of switchgrass (Panicum virgatum L., variety Cave in Rock) and jatropha (Jatropha curcas L., variety Central American) were planted in pots $\left(1400 \mathrm{~cm}^{3}\right)$ in triplicate. Black plastic pots were filled with $1250 \mathrm{~g}$ (dry weight basis) soil. The bottom of the pots was covered with nylon gauge to prevent soil loss through watering holes. Plant seeds were germinated on moist filter paper in petri dishes before being transferred to pots. Three seedlings of switchgrass and two seedlings of jatropha per pot were transferred after establishment (one week). Two plants of switchgrass and one plant of jatropha per pot were maintained throughout the experiment. Plants were fertilized every 15 days with nutrient solution $(100 \mathrm{mg}$ $\left.\mathrm{L}^{-1}\right)$ of 20-10-20 (N- $\left.\mathrm{P}_{2} \mathrm{O}_{5}-\mathrm{K}_{2} \mathrm{O}\right)$ water-soluble fertilizer. Soil water content was maintained at field capacity by irrigating every 2-3-day intervals. In greenhouse, the average daily temperature was $22-24^{\circ} \mathrm{C}$, and the photoperiod was $12 \mathrm{~h}$ of illumination per day.

Sixty days after transplanting, plants were harvested, and rhizosphere and bulk soil were collected from both types of plant. The root-soil systems were shaken in a plastic container until approximately $80 \%$ of the initial soil was collected, and this portion was considered bulk soil. The remaining soil that was attached to the root system of plants was considered rhizosphere soil. Root fragments remaining in the bulk and rhizosphere were carefully removed with the sterilized forceps. Both types of soil sample were stored in plastic bags at $-20^{\circ} \mathrm{C}$ prior to analysis.

2.3. Analytical Procedures. PLFAs from soil were extracted in three steps using the protocols of Bardgett et al. [6] and Frostegård et al. [7]. In brief, lipids were extracted from soil using citrate buffer, chloroform, and methanol at a ratio of $0.8: 1: 2$ and then fractionated into neutral, glycol, and phospholipids on silicic acid columns (Supelco, Inc., Bellfonte, PA). The phospholipids were then subjected to alkaline methanolysis and were analyzed by HewlettPackard 5890 Series II gas chromatograph (GC) (Palo Alto, CA) equipped with a HP Ultra 2 capillary column and a flame ionization detector (FID-GC). The measurement was done with MISystem, Version 4.5 (MIDI Inc., Newark, DE), using the TSBA 40 method. Methyl nonadecanoate served as an internal standard, which allowed calculation of FAME concentrations [8].

Total bacterial, fungal, and actinomycetes PLFAs were calculated using both, absolute (nmole per $\mathrm{g}^{-1}$ soil) and relative abundances (mole percent of PLFA total). The summed masses of PLFAs (nmol PLFA $\mathrm{g}^{-1}$ soil) reported as typical of fungi (18:2 $\omega 6,9 \mathrm{c})$, Gram-negative (GM-) bacteria (cy17:0, $16: 1 \omega 7,18: 1 \omega 7,17: 1 \omega 9)$, Gram-positive (GM+) bacteria (i15:0, a15:0, i16:0, i17:0, a17:0), and actinomycetes (16:0 $10 \mathrm{Me}, 17: 010 \mathrm{Me}, 18: 010 \mathrm{Me})[8,9]$ were used as signature biomarkers for these microbial groups.

2.3.1. DNA Extraction and LH-PCR Analysis. The Fast DNA Spin kit (MP Biomedicals, Solon, $\mathrm{OH}$ ) designed to extract PCR-ready genomic DNA from bacteria, fungi, plants, and animals in a soil community was used in this study to extract DNA from soil samples $(0.5 \mathrm{~g})$. Briefly, cells were lysed with detergents, silica, and ceramic beads and by homogenization (Fast DNA Pre System). Additional purification steps were performed in order to remove other contaminants. The GENECLEAN procedure was done as the final purification step. Purified DNA was stored at $-20^{\circ} \mathrm{C}$. The amplification of eubacterial sequences was performed on $10 \mathrm{ng}$ DNA, using fluorescently labeled forward primer $27 \mathrm{~F}\left(5^{\prime}\right.$ [6FAM] AGAGTTTGATCCTGGCTCAG-3') [10] and unlabeled reverse primer 338R ( $5^{\prime}$ GCTGCCTCCCGTAGGAGT$3^{\prime}$ ) [11]. The PCR mixture $50 \mu \mathrm{L}$ (final volume) contained soil DNA, $1 \times$ Taq master mix (PCR buffer, $1.5 \mathrm{mM} \mathrm{MgCl}$, $0.2 \mathrm{mM}$ dNTPs, 25 unit $\mathrm{mL}^{-1}$ Taq DNA polymerase) (New England Biolabs, Inc.), 0.06\% bovine serum albumin, and each primer at a concentration of $0.25 \mu \mathrm{M}$. The PCR reaction consisted of initial denaturation at $94^{\circ} \mathrm{C}$ for $3 \mathrm{~min}$ 
followed by 40 cycles of denaturation at $94^{\circ} \mathrm{C}$ for $45 \mathrm{~s}$, annealing at $55^{\circ} \mathrm{C}$ for $45 \mathrm{~s}$, and extension at $72^{\circ} \mathrm{C}$ for $2 \mathrm{~min}$. The final extension step consisted of $72^{\circ} \mathrm{C}$ for $7 \mathrm{~min}$. PCR products were purified with QIA quick spin columns (Qiagen, Valencia, CA). Purified LH-PCR products were visualized on $1 \%$ agarose gels stained with ethidium bromide. Samples of purified PCR products were submitted to Plant-Microbe Genomics Facility, The Ohio State University, for the LH-PCR fragments analysis on Applied Biosystems 3730 DNA Analyzer (Applied Biosystems, Inc.). Size and relative abundance of LH-PCR fragments were calculated using GeneMapper v4.0 software and Peak Scanner (Applied Biosystems, Inc.).

2.4. Statistical Analysis. The relative peak areas of LH-PCR fragment data and PLFA (molar \%) were analyzed using the principal component analysis (PCA) option in the statistical analysis package of PC ORD [12]. The PCA scores were then analyzed by two-way ANOVA if plant, soil, or their interaction resulted in significant differences $(P<0.05)$. The PLFA was analyzed by two-way ANOVA for significant differences between plant, soils, and their interactions.

Diversity indices were calculated as follows: Richness $(S)=$ number of LH-PCR fragment or PLFAs; Evenness $(E)=H / \ln$ (richness); Shanon index $(H)=-\Sigma p_{i} \ln \left(p_{i}\right)$, where $p_{i}$ is the relative abundance of a given LH-PCR fragment or PLFA.

\section{Results}

3.1. PLFA Profile of Soil Microbial Communities of Switchgrass and Jatropha. A variety of PLFA(s) (31 distinct types) were obtained from the rhizosphere and bulk soils of both switchgrass and jatropha soils, which included saturated, unsaturated, methyl-branched, and cyclopropane fatty acids (Figure 1). Two-way analysis of variance of individual PLFA resulted in significant $(P<0.05)$ differences for most of the fatty acids. In general, there were more significant effects for plants than of soils. Switchgrass soil contained significantly higher molar percent of $14: 0,15: 0$, i14:0, i15:1, i15:0 a15:0, 16:1 $\omega 9 \mathrm{c}, 16: 1 \omega 5 \mathrm{c}, 16: 1 \omega 7 \mathrm{c}$, and $18: 1 \omega 5 \mathrm{c}$

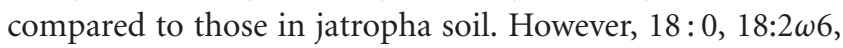
$9 c, 18: 1 \omega 9 c$, and 20:1 $\omega 9 \mathrm{c}$ PLFA, were significantly higher in jatropha soils compared to those of switchgrass soil. Irrespective of the plant, $16: 0,18: 0,20: 0,116: 0,10 \mathrm{Me} 17: 0$,

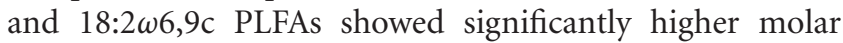
percents in rhizosphere soil compared to bulk soil; whereas $14: 0,16: 1 \omega 9 c, 16: 1 \omega 5 c, 16: 1 \omega 7 c$, and 18:1 199 c PLFAs were significantly higher molar percents in bulk soil compared to those of rhizosphere soil. In interaction effects, switchgrass bulk soil contained significantly more of $20: 0$ and $20: 1 \omega 9 c$ compared to other soils (Figure 1).

The microbial community structures of jatropha and switchgrass soils were determined by performing PCA on the PLFAs of their rhizosphere and bulk soils (Figure 2). The PCA analysis of the PLFAs clearly separated the four soils (Figure 2). The first two principle components explained $59 \%$ of the variation in the data. Score of Axis 1 showed significant $(P<0.05)$ difference in PLFA profiling of soils and plants. For PCA Axis 1, on the basis of correlation, the important PLFAs were $16: 0,18: 0,18: 2 \omega 6,9 \mathrm{c}$ (fungi), $18: 1 \omega 5 \mathrm{c}(\mathrm{GM}-)$, and $20: 1 \omega 9 \mathrm{c}$ in positive direction and $14: 0,15: 0, \mathrm{i} 15: 1, \mathrm{i} 14: 0(\mathrm{GM}+)$, i15:0 (GM+), a15:0 (GM+), $16: 1 \omega 9 \mathrm{c}(\mathrm{GM}-), 16: 1 \omega 5 \mathrm{c}(\mathrm{GM}-)$, and $16: 1 \omega 7 \mathrm{c}(\mathrm{GM}-)$ in negative direction. For PCA Axis 2, the important PLFAs were i16:0, i17:0, a17:0 (GM+), cy19:0 (GM-), 16:0 10Me, $17: 010 \mathrm{Me}, 18: 010 \mathrm{Me} 1018: 0$ (all actinomycetes), 18:0, and $17: 1 \omega 8$ in the positive direction and $18: 3 \omega 6 \mathrm{c}$ and $18: 2 \omega 6$, $9 \mathrm{c}$ (fungi) in negative direction.

3.2. LH PCR Analysis of Soil Microbial Communities of Switchgrass and Jatropha. The LH-PCR analysis resulted in 17 to 19 fragments per rhizosphere and bulk soil of jatropha or switchgrass. The LH-PCR fragments size varied from 310 to 369 base pair in switchgrass and jatropha soils (data not shown). However, these PCR results cannot be considered to be quantitative, and therefore no ANOVA was performed. On a qualitative basis, jatropha soil contained higher relative peak area (\%) for fragments 310, 315, $321,326,340,346,348,349$, and 352 bp length compared to those in switchgrass soil, whereas LH-PCR fragments 313 and $343 \mathrm{bp}$ lengths were higher in switchgrass soil compared to jatropha soil. Irrespective of plants, relative peak area of fragments $331,337,349,352$, and $357 \mathrm{bp}$ length showed higher in rhizosphere soil compared to bulk soil; whereas, 310, 313, 321, 326, 344, and 348 bp lengths were significantly higher in bulk soil compared to rhizosphere soil.

The PCA analysis of the LH-PCR fragments clearly separated the soils (Figure 3 ). The first two principle components analysis explained $35 \%$ of variability. PCA scores of Axis 1 significantly $(P<0.05)$ differentiated the rhizosphere and bulk of switchgrass but both soils of jatropha were nonsignificant to each other. PCA scores of Axis 2 differentiated relative peak area of LH-PCR fragments on the basis of plants and soils. Correlation of PCA Axis 1 showed that the important fragments were $310,313,321$, and 326 in the positive direction and 324,331,343, and 357 in the negative direction. For PCA Axis 2, the important fragments were 315, $321,326,340,349$, and 352 in the positive direction and 313 and 354 in the negative direction.

3.3. Diversity Indices. Table 1 shows the diversity indices for PLFA and LH-PCR data of soil microbial communities of switchgrass and jatropha. Based on diversity indices, rhizosphere and bulk soil did not differ significantly in both switchgrass and jatropha, as the diversity indices for PLFA and LH-PCR data of rhizosphere and bulk soil of both crops were similar, except for Shannon's diversity index, $\mathrm{H}$, in case of PLFA. Significantly $(P<0.05)$ higher Shannon's diversity index was observed for PLFA data for rhizosphere and bulk soils of switchgrass compared to jatropha soils. Higher diversity was observed for PLFA data compared to LH-PCR data for both switchgrass and jatropha soils, as shown by higher richness and Shannon's diversity index for PLFA data compared to LH-PCR data for both soils. 


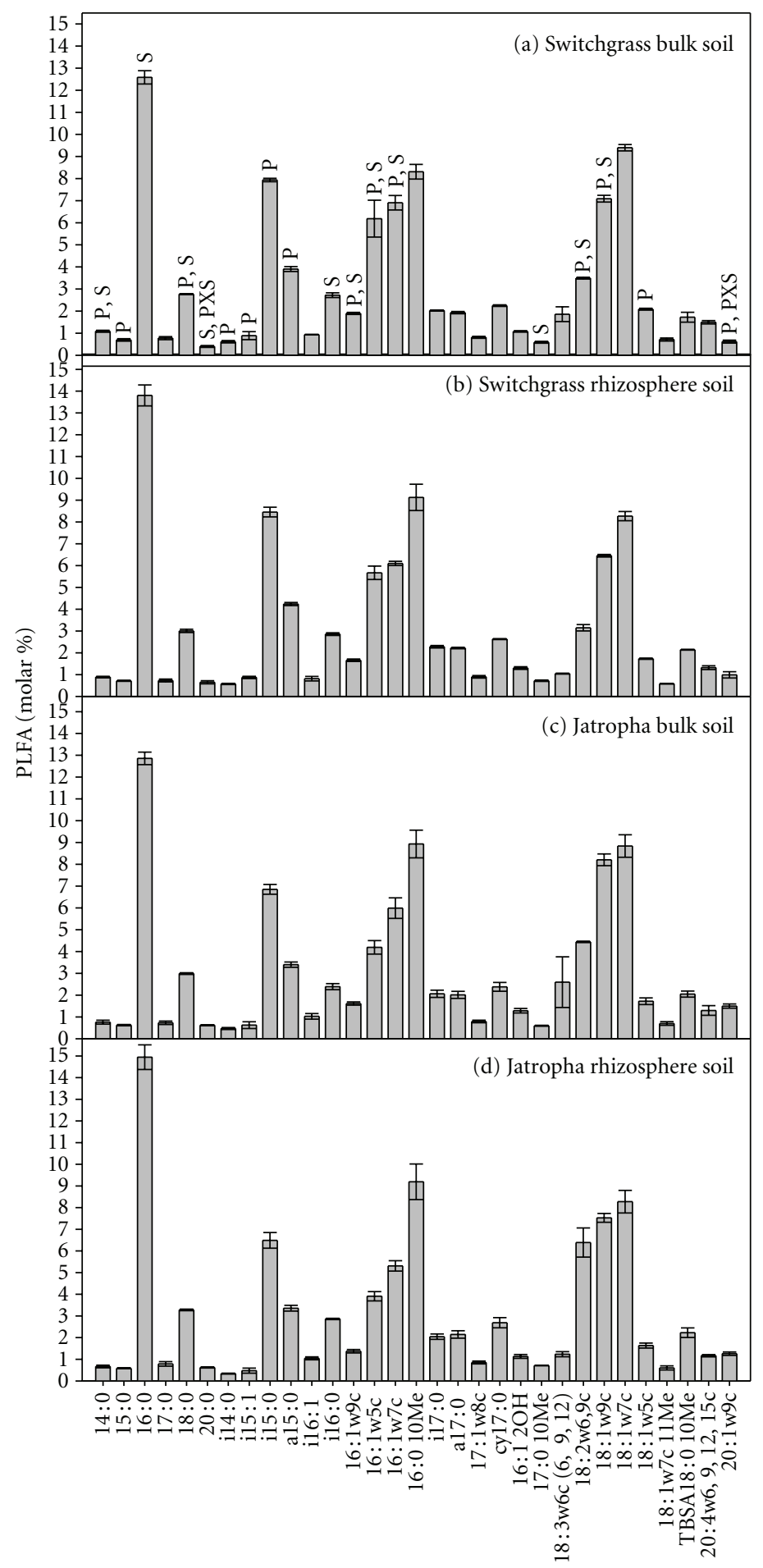

PLFAs

FIGURE 1: Mole percentage of PLFAs in bulk and rhizosphere soils of switchgrass and jatropha. Error bars indicate standard error. Significant $(P<0.05)$ differences of individual PLFAs between plant $(P$; jatropha and switchgrass), soil ( $S$; rhizosphere and bulk), and their interaction (SXP) are presented in the Figure 1(a).

\section{Discussion}

Both PLFA and LH-PCR analysis distinguished the microbial communities between the rhizosphere and bulk soil of switchgrass and jatropha, where PCA explained 59 and $34 \%$ of variability in PLFA and LH-PCR data, respectively (Figures 2 and 3). PCA Axis 1 distinguished the microbial profiles based on soil, when PLFA data was used (Figure 2); 
TABLE 1: Diversity indices calculated from PLFA and LH-PCR data. Means followed by the same letters ( $a$, b) in a column with method differ significantly.

\begin{tabular}{llccc}
\hline Method & Soil & Richness $(S)$ & Evenness $(E)$ & Shannon's diversity index $(H)$ \\
\hline \multirow{4}{*}{ PLFA } & Bulk (switchgrass) & 33.00 & 0.87 & $3.07 \mathrm{a}$ \\
& Rhizosphere (switchgrass) & 33.66 & 0.88 & $3.08 \mathrm{a}$ \\
& Bulk (jatropha) & 32.26 & 0.87 & $3.01 \mathrm{~b}$ \\
& Rhizosphere (jatropha) & 32.33 & 0.88 & $3.02 \mathrm{~b}$ \\
\multirow{2}{*}{ LH-PCR } & Bulk (switchgrass) & 17.66 & 0.85 & 2.49 \\
& Rhizosphere (switchgrass) & 18.33 & 0.88 & 2.53 \\
& Bulk (jatropha) & 18.00 & 0.89 & 2.55 \\
\hline
\end{tabular}

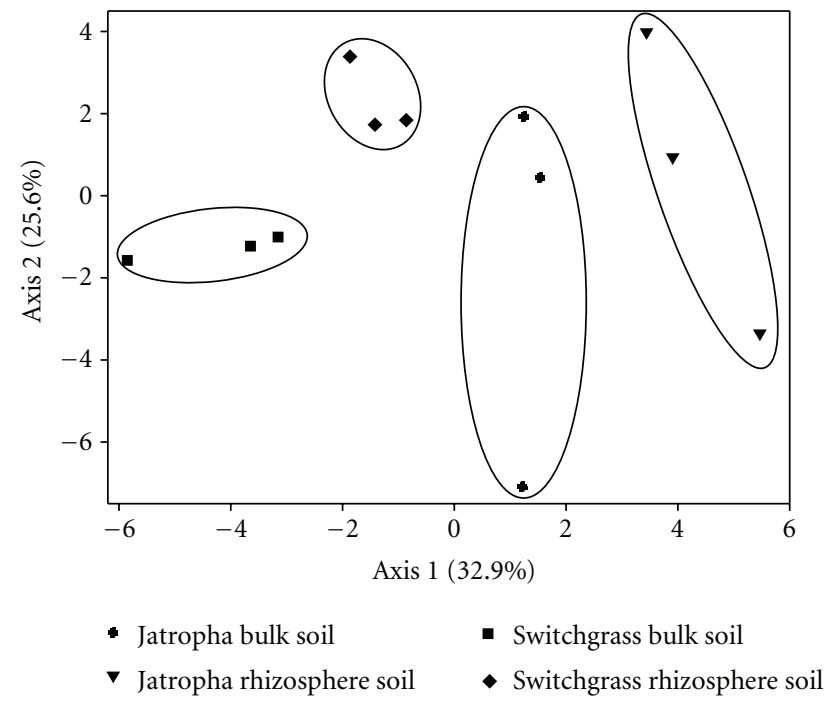

Figure 2: Principle component analysis of PLFA data from rhizosphere and bulk soils of switchgrass and jatropha.

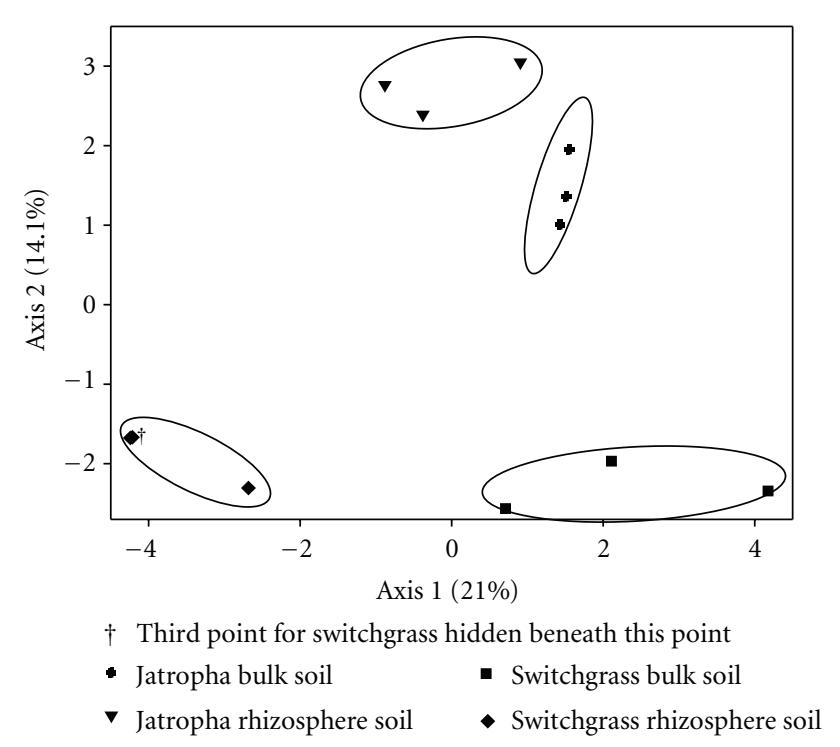

FIGURE 3: Results of principle component analysis of LH-PCR relative peak area of fragment size from rhizosphere and bulk soils of switchgrass and jatropha. whereas PCA Axis 2 distinguished the microbial profiling on basis of plant, when LHPCR data was used (Figure 3). The data were more effective in separating the rhizosphere and bulk soil of switchgrass than in case of jatropha.

PLFA analysis of soil has been extensively used to study the soil microbial community $[13,14]$. PLFA analysis is advantageous over other methods like 16S rRNA (rDNA) analysis because it is less labor intensive and is readily quantitative in detecting the size of microbial functional groups [8, 15]. PLFA analysis, however, does not identify the microorganisms to species and strain level, unless there is a unique lipid serving as a true biomarker of a given microbial strain.

Rhizosphere soil contained higher microbial biomass compared to bulk soil, which is likely due to greater availability of substrates for microbial growth via root exudation [16]. This results in an increased population density and community structure in rhizosphere that may be distinct from that in bulk soil. A variety of microbial PLFAs representative of fungi, actinomycetes, and GM+ and GM- bacteria were identified from the soils of jatropha and switchgrass (Figure 1). In the rhizosphere soils, PLFAs representative of actinomycetes (10Me17:0) and fungi $(18: 2 \omega 6,9 \mathrm{c})$ were in significantly higher abundance $(P<0.05)$ than in bulk soil; whereas $16: 1 \omega 9 c, 16: 1 \omega 5 c, 16: 1 \omega 7 \mathrm{c}$ PLFAs representative of GM- [8] were in greater abundance in bulk soil (Figure 1). The levels of fungi in the rhizosphere should contribute to higher soil quality as fungal hyphae promote aggregation of soils [17].

The plant species effect on microbial community structure in rhizospheres is due to differences in root exudation and rhizodeposition in different root zones [3]. The branched chain PLFAs (i14:0, i15:0, a15:0), characteristic of GM+ bacteria [18] and monounsaturated PLFAs (16:1 $\omega 5 \mathrm{c}$, $16: 1 \omega 7 \mathrm{c}$ and $18: 1 \mathrm{w} 5 \mathrm{c}$ ), characteristics of GM- bacteria [18] were higher in switchgrass soils compared to those in jatropha soils, whereas the rhizosphere and bulk soils of jatropha contained higher amount of polyunsaturated PLFAs $(18: 2 \omega 6,9 \mathrm{c}$ and $18: 1 \omega 9 \mathrm{c})$, indicative of fungi [8] compared to those in switchgrass.

In general, rhizosphere and bulk soil of switchgrass contained higher amounts of branched chain PLFAs (i15:0, a15:0), characteristic of GM+ bacteria [18], and monounsaturated $(16: 1 \omega 5 c, 16: 1 \omega 7 c$, and 18:1w5c) PLFAs, whereas the jatropha soil contained a higher amount of

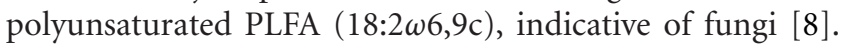


The differences in microbial community of these two plants are probably due to the differences in root exudation. Higher abundance of 16:0 and other straight chain saturated PLFA were observed in the soil of both switchgrass and jatropha, which were in relatively higher abundance in rhizosphere soil than in bulk soil. These PLFAs might be of nonmicrobial origin, as they may also come from other eukaryotes such as higher plants [8]. Sloughing of roots cells during root growth, an element of rhizodeposition could have contributed to the presence of these lipids. Differences in PLFA profiling reflect differences in the quality and quantity of rhizodeposition and root architecture (surface area, depth of root penetration, etc.).

Similar to PLFA analysis, LH-PCR is relatively easy, quick, and reproducible compared to other, more involved or cumbersome molecular techniques (e.g., clone library, TRFLP, and DGGE) [5]. However, LH-PCR in our study could not be confirmed to be quantitative. But, like PLFA, it distinguished soil communities as a function of rhizosphere versus bulk soil and between rhizospheres of the two plant species using multivariate, PCA analysis. LH-PCR profiling did poorly in separating jatropha rhizosphere and bulk soils. The Shannon analysis showed PLFA having greater diversity than LH-PCR on the same soil samples. This may be due in part to PLFA analysis measuring the whole microbial community at the functional level whereas LH-PCR represents only the bacterial community. Secondly, PLFA comes from viable cells and is readily extractable, compared to LH-PCR, which analyzes DNA, some of which could have come from free DNA exclusive of viable cells, in the soil matrix. Another advantage of PLFA method is that it directly provides information on the community composition. To get such information from the LH-PCR method, further sequencing of fragments would be necessary.

The results of this study support a significant role for the rhizosphere in influencing microbial community structure in soils of bioenergy crops. This study also indicated that PLFA technique is effective in terms of distinguishing microbial communities in rhizosphere and bulk soils of switchgrass and jatropha.

\section{Acknowledgment}

This work was supported in part by the Department of Science and Technology, Government of India, in the form of BOYSCAST fellowship to D. R. Chaudhary.

\section{References}

[1] B. D. Solomon, "Biofuels and sustainability," Annals of the New York Academy of Sciences, vol. 1185, pp. 119-134, 2010.

[2] P. Hinsinger, A. G. Bengough, D. Vetterlein, and I. M. Young, "Rhizosphere: biophysics, biogeochemistry and ecological relevance," Plant and Soil, vol. 321, no. 1-2, pp. 117-152, 2009.

[3] J. Sørensen, "The rhizosphere as a habitat for soil microorganisms," in Modern Soil Microbiology, J. D. Van Elsas, J. T. Trevors, and E. M. H. Wellington, Eds., pp. 21-45, Marcel Dekker, New York, NY, USA, 1997.
[4] C. T. Green and K. M. Scow, "Analysis of phospholipid fatty acids (PLFA) to characterize microbial communities in aquifers," Hydrogeology Journal, vol. 8, no. 1, pp. 126-141, 2000.

[5] N. J. Ritchie, M. E. Schutter, R. P. Dick, and D. D. Myrold, "Use of length heterogeneity PCR and fatty acid methyl ester profiles to characterize microbial communities in soil," Applied and Environmental Microbiology, vol. 66, no. 4, pp. 1668-1675, 2000.

[6] R. D. Bardgett, P. J. Hobbs, and A. Frostegård, "Changes in soil fungal:bacterial biomass ratios following reductions in the intensity of management of an upland grassland," Biology and Fertility of Soils, vol. 22, no. 3, pp. 261-264, 1996.

[7] A. Frostegård, E. Bååth, and A. Tunlio, "Shifts in the structure of soil microbial communities in limed forests as revealed by phospholipid fatty acid analysis," Soil Biology and Biochemistry, vol. 25, no. 6, pp. 723-730, 1993.

[8] L. Zelles, "Fatty acid patterns of phospholipids and lipopolysaccharides in the characterisation of microbial communities in soil: A review," Biology and Fertility of Soils, vol. 29, no. 2, pp. 111-129, 1999.

[9] J. Moore-Kucera and R. P. Dick, "PLFA profiling of microbial community structure and seasonal shifts in soils of a Douglasfir chronosequence," Microbial Ecology, vol. 55, no. 3, pp. 500$511,2008$.

[10] R. E. Hicks, R. I. Amann, and D. A. Stahl, "Dual staining of natural bacterioplankton with 4,6-diamidino-2- phenylindole and fluorescent oligonucleotide probes targeting kingdomlevel 16S rRNA sequences," Applied and Environmental Microbiology, vol. 58, no. 7, pp. 2158-2163, 1992.

[11] R. I. Amann, L. Krumholz, and D. A. Stahl, "Fluorescentoligonucleotide probing of whole cells for determinative, phylogenetic, and environmental studies in microbiology," Journal of Bacteriology, vol. 172, no. 2, pp. 762-770, 1990.

[12] B. McCune and M. J. Mefford, PC-ORD. Multivariate Analysis of Ecological Data. Version 5, MjM Software, Gleneden Beach, Ore, USA, 2006.

[13] N. Nunan, B. Singh, E. Reid et al., "Sheep-urine-induced changes in soil microbial community structure," FEMS Microbiology Ecology, vol. 56, no. 2, pp. 310-320, 2006.

[14] A. M. Treonis, N. J. Ostle, A. W. Stott, R. Primrose, S. J. Grayston, and P. Ineson, "Identification of groups of metabolically-active rhizosphere microorganisms by stable isotope probing of PLFAs," Soil Biology and Biochemistry, vol. 36, no. 3, pp. 533-537, 2004.

[15] D. C. White and R. H. Findlay, "Biochemical markers for measurement of predation effects on the biomass, community structure, nutritional status, and metabolic activity of microbial biofilms," Hydrobiologia, vol. 159, no. 1, pp. 119132, 1988.

[16] K. H. Söderberg and E. Bååth, "Bacterial activity along a young barley root measured by the thymidine and leucine incorporation techniques," Soil Biology and Biochemistry, vol. 30, no. 10-11, pp. 1259-1268, 1998.

[17] V. V. S. R. Gupta and J. J. Germida, "Distribution of microbial biomass and its activity in different soil aggregate size classes as affected by cultivation," Soil Biology and Biochemistry, vol. 20, no. 6, pp. 777-786, 1988.

[18] G. P. Zogg, D. R. Zak, D. B. Ringelberg, N. W. MacDonald, K. S. Pregitzer, and D. C. White, "Compositional and functional shifts in microbial communities due to soil warming," Soil Science Society of America Journal, vol. 61, no. 2, pp. 475-481, 1997. 

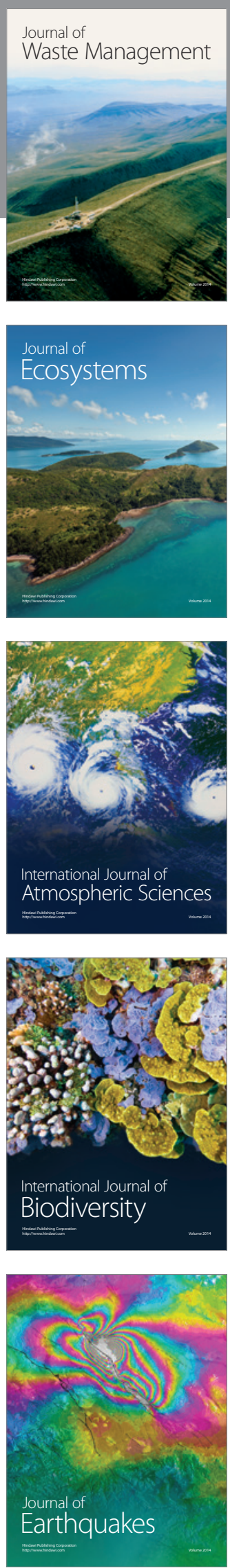
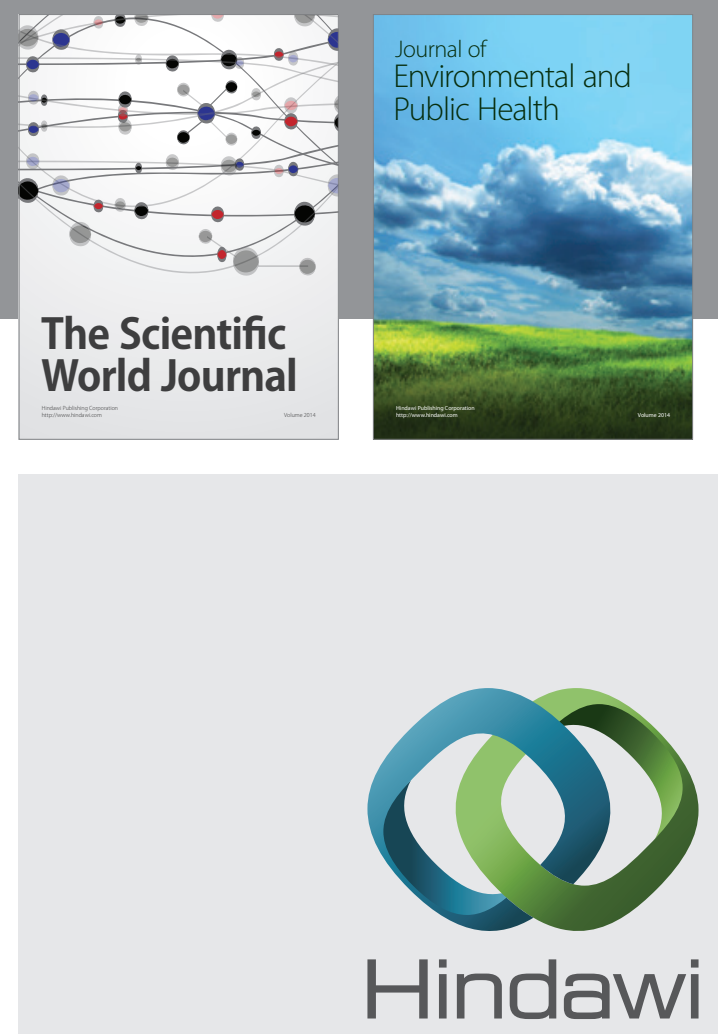

Submit your manuscripts at

http://www.hindawi.com
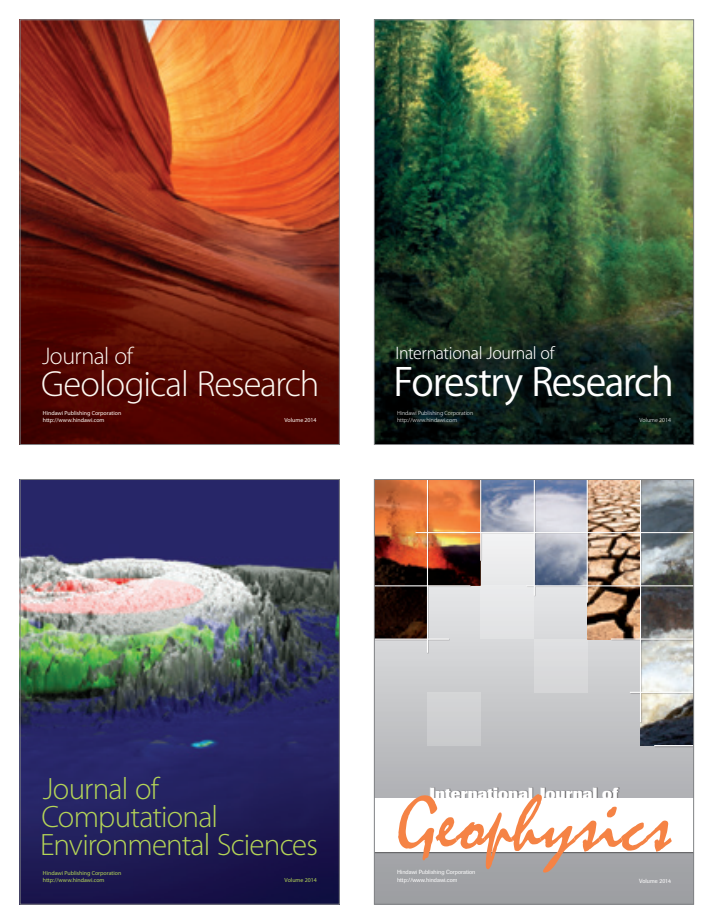
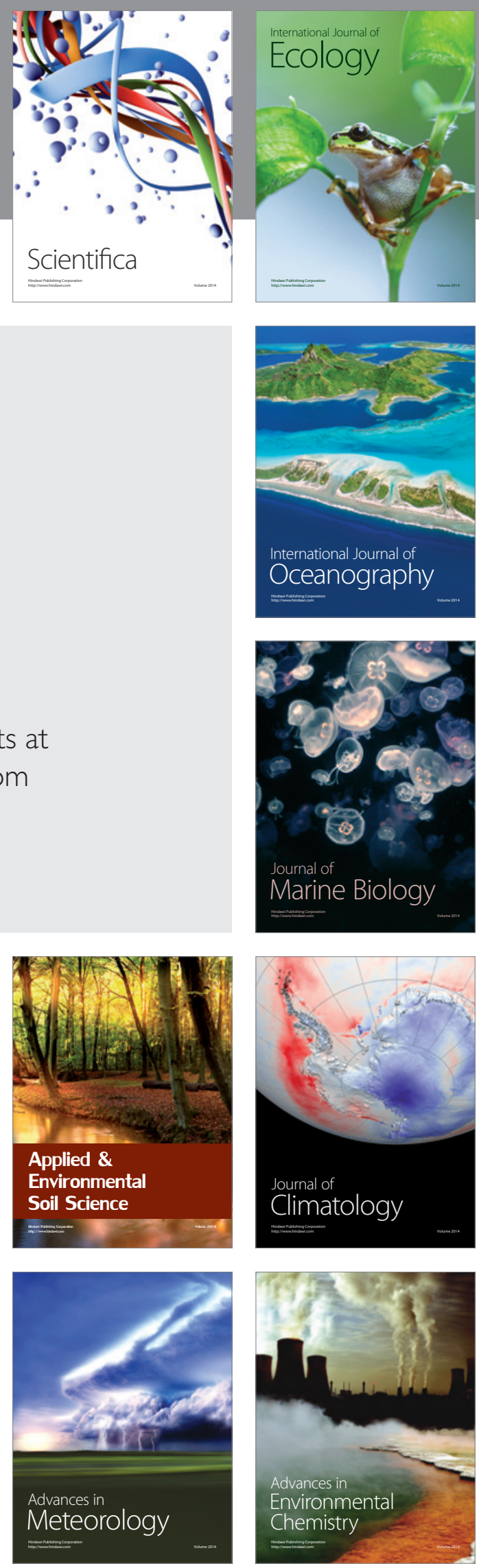